\title{
The Human Invasive Cysticercosis by Atypical Taenia Species
}

\author{
Viroj Wiwanitkit ${ }^{1{ }^{*}}$ \\ ${ }^{1}$ Visiting Professor, Hainan Medical University, China \\ "Corresponding author: Visiting Professor, Hainan Medical University, China. E-mail: wviroj@yahoo.com
}

Received 2017 February 08; Revised 2017 October 10; Accepted 2017 October 21.

Keywords: Cysticercosis, Taenia Species

\section{Dear Editor,}

Taenia genus is the group of parasites that can cause infection in humans. The invasive form of the infection is possible and can cause the internal parasitic cystic lesion namely cysticercosis. The cysticercosis lesion can be observed at any organ and the most fatal lesion is at the brain, which is clinically known as cerebral neurocysticercosis. At least three common species can cause neurocysticercosis including Taenia solium, T. asiatica, and T. martis (1). Recently, T. multiceps also proposed as a new species causing neurocysticercosis (2) and ship is its intermediate host (2).

Nevertheless, there are also other atypical species that can cause invasive cysticercosis in internal organs of human beings. Those species are usually forgotten human infections. The case of $T$. crassiceps infection is already mentioned for its importance due to causing invasive cysticercosis in the cases with immune deficiency (3-5). The infection is a zoonosis from fox (2-4). According to a recent report on human cysticercosis from Germany (5), there is an additional species considered as the fifth species, T. serialis (coenurosis) that can cause invasive cystcercosis in human beings. In the same study (5), T. crassiceps was also detected. The two species, T. crassiceps and T. serialis (coenurosis), are interesting uncommon findings (5). The clinical presentations of the two species are similar to the other species that can cause human cysticercosis. The silent internal cystic lesion, usually accidentally detected, is the most common clinical presentation. The diagnosis is usually due to the examination of excision specimen by molecular diagnosis. The new species are considered emerging zoonosis from dog. Based on the author's experience in a tropical country, Thailand, the diagnosis of atypical cysticercosis seems to be difficult, since the pathological laboratories usually diagnose the cysticercosis without species classification.

\section{References}

1. Joob B, Wiwanitkit V. Cerebral Neurocysticercosis due to Taenia martis, the Third Species That Needs Attention. Arch Neuroscience. 2016;3(1). doi: 10.5812/archneurosci.31856.

2. El-On J, Shelef I, Cagnano E, Benifla M. Taenia multiceps: a rare human cestode infection in Israel. Vet Ital. 2008;44(4):621-31. [PubMed: 20411489].

3. Francois A, Favennec L, Cambon-Michot C, Gueit I, Biga N, Tron F, et al. Taenia crassiceps invasive cysticercosis: a new human pathogen in acquired immunodeficiency syndrome? AmJSurg Pathol. 1998;22(4):488-92. [PubMed: 9537478].

4. Chermette R, Bussieras J, Marionneau J, Boyer E, Roubin C, Prophette B, et al. [Invasive cysticercosis due to Taenia crassiceps in an AIDS patient]. Bull Acad Natl Med. 1995;179(4):777-80. discussion 780-3. [PubMed: 7648312].

5. Maillard H, Marionneau J, Prophette B, Boyer E, Celerier P. Taenia crassiceps cysticercosis and AIDS. AIDS. 1998;12(12):1551-2. [PubMed: 9727578]. 